\title{
Relationship between intensity of night shift work and antioxidant status in blood of nurses
}

\author{
Jolanta Gromadzińska • Beata Peplonska • \\ Wojciech Sobala Edyta Reszka - Wojciech Wasowicz • \\ Agnieszka Bukowska $\cdot$ Jenny-Anne Lie
}

Received: 6 December 2011/ Accepted: 26 October 2012/Published online: 23 November 2012

(C) The Author(s) 2012. This article is published with open access at Springerlink.com

\begin{abstract}
Purpose Light-at-night exposure can disrupt the human circadian rhythm via clock gene expressions. The circadian rhythm influences antioxidant enzymes' activity and cellular mRNA levels of these enzymes. The employees working based on a shift system adjust to the changes occurring both on the cell level and on the level of the whole organism. Therefore, a question should be answered whether shift work disturbs oxidant-antioxidant balance and/or generates oxidative stress.

Methods A cross-sectional study was conducted among nurses selected from the Local Registry of the Chamber of Nurses and Midwives in Lodz: 359 nurses worked daily only and 349 working rotating night shifts. These two groups differed significantly in respect of age $(p<0.0001)$, menopausal status $(p<0.0001)$, and current smoking habit $(p=0.02)$. The average total work duration was significantly shorter (12.4 years) in nurses working currently rotating night shifts who worked significantly longer on night shifts than day-workers (26.6 years).

Results We found statistically significant higher red blood cell glutathione peroxidase in nurses working on night shifts $(21.0 \pm 4.6$ vs. $20.0 \pm 5.0 \mathrm{U} / \mathrm{g} \mathrm{Hb}, p<0.009)$ after adjusting for age, oral contraceptive hormone use, smoking, and drinking alcohol during last $24 \mathrm{~h}$. Statistically significant lower vitamin A and E levels were found
\end{abstract}

The authors have made equal contributions to this work.

J. Gromadzińska ( $₫) \cdot$ B. Peplonska · W. Sobala · E. Reszka ·

W. Wasowicz · A. Bukowska

Nofer Institute of Occupational Medicine, Lodz, Poland

e-mail: jola@imp.lodz.pl

J.-A. Lie

Institute of Occupational Health, Oslo, Norway in the premenopausal women working in rotating system $(0.690 \pm 0.238$ vs. $0.786 \pm 0.262 \mu \mathrm{g} / \mathrm{ml}, p<0.0001$ for vitamin $A$ and $10.93 \pm 4.15$ vs. $12.78 \pm 4.75 \mu \mathrm{g} / \mathrm{ml}$, $p<0.0001$ for vitamin E). The marker of lipid peroxidation (TBARS concentration) was significantly lower in the premenopausal nurses than postmenopausal ones working day shifts only $(2.06 \pm 0.76$ vs. $2.21 \pm 0.80 \mathrm{nmol} / \mathrm{ml}$, $p<0.038$ ). We observed that erythrocyte GSH-Px activity rose statistically significant in nurses working more night shifts per month $(p<0.01)$.

Conclusions The results quoted above seem to support the existence of an association between light-at-night exposure and blood glutathione peroxidase activity in female shift workers. Nevertheless, in order to explain the mechanisms of this association, we need more studies.

Keywords Antioxidants - TBARS - Night shift work · Selenium $\cdot$ Light-at-night exposure

\section{Introduction}

A number of studies have investigated a possible role of environmental factors in cancer etiology. One of the factors of particular interest is exposure to light-at-night during the working hours of shift workers, which may cause sleep disruption and altered normal endocrine functions as well as health problems. According to Costa et al. (2010), the data collected in 2005 by the European Foundation for the Improvement of Living and Working Conditions showed that $21.9 \%$ of men and $10.7 \%$ of women work within a shift system that includes evening and night work. Seven per cent of shift workers permanently work at night (European Foundation for the Improvement of Living and Working Conditions 2007). It has been shown that shift 
work together with the abnormal light-dark cycle connected with it cause adverse health effects. Short-term disturbances in the normal sleep-wake cycle give reversible symptoms called a "jet-lag" syndrome (trouble with sleeping, fatigue, lack of appetite). Long-term altered light-night cycle causes chronic sleep deprivation, gastrointestinal and cardiovascular disorders, and adverse pregnancy outcome (Knutsson 2003). In several recent studies, an increase has been shown in the risk of developing cancer, in particular breast, endometrial and colon cancer, among shift workers (Schernhammer and Schulmeister 2004; Hansen 2006).

A review of epidemiological studies devoted to cancer risk in shift workers performed by Kolstad (2008) and Pauley (2004) demonstrated 36-60\% higher rates of breast cancer risk among this population. In 2007, the International Agency for Research on Cancer classified night shift work as a probable carcinogen (group 2A), based on limited evidence from human studies and adequate evidence from animal experiments (Straif et al. 2007).

Light exposure during night hours changes melatonin secretion and can disrupt the human circadian rhythm via melatonin secretion (Mirick and Davis 2008). A circadian rhythm disruption induces altered endocrine functionspossible changes in the regulation of reproductive hormone receptors-and thus it is an important factor in the etiology of hormone-related diseases, for example, breast or prostate cancer (Mirick and Davis 2008; Grant et al. 2009). Alterations in the circadian system are observed in tumor tissues during experiments with tumor bearing animals as well as in cancer patients (Mormont and Levi 1997; Cardona 2004).

The imbalance in oxidant-antioxidant levels is known to be a possible key factor in the pathogenesis of many human diseases, including breast cancer. To protect cells from oxidative damage, organisms have generated several defense mechanisms, namely enzymatic and non-enzymatic ones to remove reactive oxygen species from extraand intracellular spaces (Yeh et al. 2005; Yeon et al. 2011).

In many animal experiments, it has been shown that expression and/or activity of oxidative and antioxidative enzymes depend on the circadian rhythm (Kolanjiappan and Manoharan 2005; Baydas et al. 2002; Jimenez-Ortega et al. 2009). The circadian rhythm influences antioxidant enzymes' activity and cellular mRNA levels of these enzymes: glutathione peroxidase, superoxide dismutase (cellular and mitochondrial fraction), catalase, nitric oxide synthase, and heme oxidase (Mayo et al. 2002; Rodriguez et al. 2004; Jimenez-Ortega et al. 2009). The mechanism is unknown, but it probably follows the activation of transcriptional factors in the promoter region of antioxidative enzyme genes (Rodriguez et al. 2004).

Exposure to light-at-night results in altered endocrine functions (Mirick and Davis 2008). This is followed by generation of oxidative stress and many health disorders originating from shift work. This is followed by generation of oxidative stress and many health disorders, whose source originally is shift work. The employees working in a shift system adjust to the changes occurring both on the cell level and on the level of the whole organism. However, it has not yet been investigated whether night shift work induces changes in the concentrations/activities of antioxidants as factors with the proven association with cancer development.

The present study was carried out in a population of nurses and midwives working currently under different work schedules in order to investigate the relationship between the blood antioxidant levels (glutathione peroxidase and superoxide dismutase activity, plasma selenium, vitamin $\mathrm{A}$ and $\mathrm{E}$ levels), thiobarbituric acid reactive substances (TBARS) as a marker of pro-oxidative processes and lifestyle habits as well as work-related factors: current rotating night shift work status and frequency as well as total night shift history, age, and menopausal status.

\section{Materials and methods}

The cross-sectional study was conducted among nurses (aged 40-60) selected from the Local Registry of the Chamber of Nurses and Midwives in Lodz. Healthy women without any chronic diseases were selected for this study. After obtaining a written informed consent from each participant, information was collected during an in-person interview, regarding their occupational history, demographic characteristics, medical and reproductive history, physical activity, smoking habits, and sleep quality.

Based on the data gathered via the interview, the average frequency of night shifts at the current job was analyzed in the following categories: $0,2,4$ and 8 , or more nights per month. Additionally, we calculated the intensity of the work performed on night shifts during the whole work period.

Blood samples were collected between 06:00 and 10:00 a.m from each participant into S-Monovette ${ }^{\circledR}$ test tubes with lithium heparin as anticoagulant. In the case of night shift workers, blood collection was synchronized with the night shift, and the blood samples were collected at the end of night shift.

Glutathione peroxidase activity (GSH-Px) was determined by the method of Paglia and Valentine (1967) with $t$-butyl hydroperoxide as substrate. Superoxide dismutase (SOD) was assayed with the use of the method based on the inhibition of reduction of nitroblue tetrazolium in the presence of xanthine and xanthine oxidase (Beauchamp and Fridovich 1971). Lipid peroxidation was estimated from the measurements of TBARS levels in plasma using the method modified by Wasowicz et al. (1993). 
The plasma selenium concentration was determined by graphite furnace atomic absorption spectrometry (GFAAS) (Neve 1991). The method was validated using the reference material (lyophilized human reference serum samples of Seronorm from Nycomed Pharma AS, Oslo, Norway) and through participation in the interlaboratory comparison trials.

Vitamin E and A levels were determined by the HPLC system integrated with UV-VIS detector range 190-800 nm (Grzelinska et al. 2007).

\section{Statistical analysis}

The data from the biochemical analyses was expressed as a mean and a standard deviation.

Characteristics of the study groups were compared using the Pearson's chi-squared test and the Student's $t$ test. Linear regression model was used to analyze the relationship between antioxidants and markers of oxidative stress and night shift work. Multivariate linear regression was applied to adjust for age, oral contraceptive hormone use, smoking, and drinking alcohol during last $24 \mathrm{~h}$ as potential confounders. Following that, the interaction between night shift work and menopausal status was investigated. We used robust linear regression to validate our results against the outliers.

STATA 11 software was used to conduct all statistical analyses.

\section{Results}

The characteristics of the studied population comprising nurses and midwives are listed in Table 1. In the investigated group, at the time of the research, 359 nurses worked only daytime and 349 worked currently on rotating night shifts. These two groups differed significantly as for age $(p<0.0001)$, menopausal status $(p<0.0001)$, and current smoking habits $(p=0.02)$. The average total work duration was significantly shorter $(27.5 \pm 6.6$ years $)$ in nurses working currently on rotating night shifts than in dayworkers (29.2 \pm 6.3 years) (data not shown). The current night shift workers had, however, worked night shifts significantly longer (26.6 vs. 12.4 years).

The average period of employment under shift work conditions of women currently working rotating night shifts was significantly longer $(24.20 \pm 7.03$ years $)$ than in nurses working currently day shifts $(11.98 \pm 8.08$ years). Almost all the nurses and midwives who were current dayworkers had worked previously rotating night shifts. However, all women in that group did not work rotating shifts during the last 5 years. In the day-worker group, only 10 of the women did not work rotating shifts. The majority
(91.4\%) of currently working rotating night shift women were exposed more than 15 years to light-at-night, while about $38.0 \%$ of women currently working day shifts, worked more than 15 years under light-at-night exposure. Among the nurses currently working rotating shifts, nearly $92 \%$ work 5-8 night shifts per month, 21 women work up to 4 night shifts per month, and 8 women work above 8 night shifts per month (Table 1).

Table 2 shows markers of oxidative stress in nurses and midwives according to work system. We found statistically significant higher red blood cell glutathione peroxidase activity (RBC GSH-Px) in nurses working night shifts $(21.0 \pm 4.6$ vs. $20.0 \pm 5.0 \mathrm{U} / \mathrm{g} \mathrm{Hb}, p<0.009)$, after adjustment for age, oral contraceptive hormone use, smoking, and drinking alcohol during last $24 \mathrm{~h}$.

When antioxidant parameters in blood were analyzed according to menopausal status, we found statistically lower plasma GSH-Px activity and RBC GSH-Px activity in premenopausal nurses as compared with postmenopausal ones $(19.4 \pm 4.7$ vs. $20.6 \pm 5.1 \mathrm{U} / g \quad \mathrm{Hb}, p<0.011)$. Besides, statistically significant lower vitamin A and E levels were found in the premenopausal women working in the rotating shift system $(0.690 \pm 0.238$ vs. $0.786 \pm 0.262$ $\mu \mathrm{g} / \mathrm{ml}, p<0.0001$ for vitamin $\mathrm{A}$ and $10.93 \pm 4.15 \mathrm{vs}$. $12.78 \pm 4.75 \mu \mathrm{g} / \mathrm{ml}, \quad p<0.0001$ for vitamin $\mathrm{E})$. The marker of lipid peroxidation, TBARS concentration, was significantly lower in the premenopausal nurses than in postmenopausal ones working day shifts only $(2.06 \pm 0.76$ vs. $2.21 \pm 0.80 \mathrm{nmol} / \mathrm{ml}, p<0.038)$.

When the premenopausal nurses were categorized into day shift only and working on rotating night shift, we found statistically higher values for erythrocyte glutathione peroxidase activity in the rotating night shift nurses (Table 2). Erythrocyte GSH-Px activity was $21.0 \pm 4.8 \mathrm{U} / \mathrm{g} \mathrm{Hb}$ in premenopausal rotating night shift nurses, compared with $19.4 \pm 4.7 \mathrm{U} / \mathrm{g} \mathrm{Hb}$ in day shift workers $(p<0.011)$. As for plasma GSH-Px activity, the values for menopausal nurses working in rotating system were $0.185 \pm 0.030 \mathrm{U} / \mathrm{ml}$ and for working day shift only was $0.193 \pm 0.032 \mathrm{U} / \mathrm{ml}$, $p<0.037$.

The postmenopausal nurses working in a rotating system had higher plasma vitamin A levels compared with nurses working day shifts only (Table 2). Erythrocyte glutathione peroxidase activity was higher in premenopausal nurses working rotating night shifts than in the premenopausal subjects working days only.

Based on the data collected via the interview, we calculated the total number of night shifts during the subjects' working period. We did not find any relationship between the measured parameter of oxidative stress and cumulative shift work during the whole occupational history (Table 3).

The association between night shift work frequency per month and the antioxidant enzymes activity is presented in 
Table 1 Selected characteristics of the nurses and midwives in the cross-sectional study

\begin{tabular}{|c|c|c|c|}
\hline & $\begin{array}{l}\text { Day-workers } \\
n=359\end{array}$ & $\begin{array}{l}\text { Rotating shifts workers } \\
n=349\end{array}$ & $p$ \\
\hline Age, years & $50.2 \pm 5.3(40.1-61.1)$ & $48.3 \pm 5.2(39.5-60.2)$ & $<0.0001$ \\
\hline BMI, $\mathrm{kg} / \mathrm{m}^{2}$ & $27.1 \pm 4.7(18.5-48.3)$ & $27.1 \pm 4.6(16.4-45.2)$ & 0.98 \\
\hline Total night shift work, years & $12.4 \pm 8.3(0-37.3)$ & $26.6 \pm 7.3(4.6-42.3)$ & $<0.0001$ \\
\hline \multicolumn{4}{|c|}{ Total night shift work (categories) } \\
\hline$<5$ years & $76(21.2)$ & 0 & \multirow[t]{3}{*}{0.0001} \\
\hline $6-15$ years & $147(40.9)$ & $30(8.6)$ & \\
\hline$>15$ years & $136(37.9)$ & $319(91.4)$ & \\
\hline \multicolumn{4}{|c|}{ Current night shift work frequency per month } \\
\hline$<2$ nights & & $2(0.58 \%)$ & \\
\hline $2-4$ nights & & $19(5.44 \%)$ & \\
\hline $5-8$ nights & & $320(91.69 \%)$ & \\
\hline$>8$ nights & & $8(2.29 \%)$ & \\
\hline \multicolumn{4}{|l|}{ Smoking } \\
\hline Never smokers & $146(41.8 \%)$ & $155(43.0 \%)$ & \multirow[t]{3}{*}{0.02} \\
\hline Past smokers & $81(23.2 \%)$ & $110(30.6 \%)$ & \\
\hline Current smokers & $122(35.0 \%)$ & $95(26.4 \%)$ & \\
\hline \multicolumn{4}{|l|}{ Menopausal status } \\
\hline Pre- & $185(51.5 \%)$ & $225(65.7 \%)$ & \multirow[t]{2}{*}{$<0.0001$} \\
\hline Post- & $174(48.5 \%)$ & $124(34.3 \%)$ & \\
\hline \multicolumn{4}{|c|}{ Current oral contraceptives or sex hormone use } \\
\hline Yes & $89(24.8 \%)$ & $80(23.0 \%)$ & \multirow[t]{2}{*}{0.513} \\
\hline No & $270(75.2 \%)$ & $269(77.0 \%)$ & \\
\hline
\end{tabular}

Fig. 1. We observed that the erythrocyte GSH-Px activity rose statistically significant in nurses working on more night shifts per month $(p<0.001)$. The association between plasma GSH-Px activity and night shift work differed significantly between pre- and postmenopausal nurses: it was higher $(p<0.008)$ in the premenopausal subjects and lower $(p<0.024)$ in the postmenopausal ones (Fig. 2).

\section{Discussion}

A number of clinical and experimental studies have indicated that exposure to a number of physical and/or chemical agents may generate reactive oxygen species (ROS) and promote oxidative stress. ROS react with unsaturated fatty acids of cell membranes, as well as with proteins and nucleic acid and may play an indirect role in disease development (Valko et al. 2004). Mammalian cells have different antioxidant systems including various antioxidative enzymes comprise the necessary trace elements ( $\mathrm{Se}, \mathrm{Zn}, \mathrm{Cu}, \mathrm{Mn}$ ), as well as low-molecular-weight antioxidants: vitamin $\mathrm{A}, \mathrm{E}, \mathrm{C}$, glutathione, uric acid, etc. (Polat et al. 2002). It has been observed in animal experiments that antioxidant enzyme activities and their gene expression exhibit cyclic $24 \mathrm{~h}$ rhythm under normal light-dark conditions. Experiments with rats and chicken have shown that brain GSH-Px and SOD activity is higher at night-time than at day-time (Pablos et al. 1998; Albarrán et al. 2001).

On the other hand, Baydas et al. $(2001,2002)$ found that constant exposure to light decreases the GSH-Px activity in rat brain, liver, and kidney. Circadian variations of brain enzymes have been described for many redox state controlling enzymes (Jimenez-Ortega et al. 2009). Twentyfour hour changes in the enzyme activity suggest that this cycle may be dependent on the circadian melatonin rhythm (Baydas et al. 2002).

In the group of 349 nurses working within a rotating night and day shifts system, we found significantly higher RBC GSH-Px activity $(p<0.009$ after adjustment for age, oral contraceptive hormone use, smoking and drinking alcohol during the last $24 \mathrm{~h}$ ). Moreover, a progressive increase was found to occur in the RBC GH-Px activity related to the frequency of night shifts per month (Fig. 1, $p<0.001)$. Such clear, statistically significant, changes were demonstrated only for the activity of RBC GSH-Px in the premenopausal nurses. For the postmenopausal subjects, the changes were not statistically significant.

The remaining studied parameters (markers of antioxidative processes and TBARS) did not differ between study groups working in different work systems. In female 
Table 2 Antioxidant and TBARS levels in the blood of nurses and midwives working currently within the rotating night shifts system or during the day only
Results expressed as mean \pm SD

Statistically significant differences are given in bold

* Adjusted for age, oral contraceptive hormone use, smoking, and drinking alcohol during the last $24 \mathrm{~h}$

\begin{tabular}{|c|c|c|c|c|}
\hline Parameters & $\begin{array}{l}\text { Day shift } \\
n=359 \\
(185 / 174)\end{array}$ & $\begin{array}{l}\text { Rotating nights } \\
n=349 \\
(225 / 124)\end{array}$ & $p$ crude & $p$ adjustment $*$ \\
\hline \multicolumn{5}{|c|}{ Plasma GSH-Px activity, U/ml } \\
\hline All & $0.188 \pm 0.030$ & $0.188 \pm 0.033$ & 0.952 & 0.974 \\
\hline Premenopause & $0.182 \pm 0.032$ & $0.189 \pm 0.030$ & 0.029 & 0.137 \\
\hline Postmenopause & $0.193 \pm 0.032$ & $0.185 \pm 0.030$ & 0.024 & $\mathbf{0 . 0 3 7}$ \\
\hline$p$ (pre: postmenopause)* & 0.001 & 0.310 & & \\
\hline \multicolumn{5}{|c|}{ RBC GSH-Px activity, $\mathrm{U} / \mathrm{g} \mathrm{Hb}$} \\
\hline All & $20.0 \pm 5.0$ & $21.0 \pm 4.6$ & 0.006 & 0.009 \\
\hline Premenopause & $19.4 \pm 4.7$ & $21.0 \pm 4.8$ & 0.001 & 0.011 \\
\hline Postmenopause & $20.6 \pm 5.1$ & $21.0 \pm 4.4$ & 0.554 & 0.331 \\
\hline$p$ (pre: postmenopause)* & 0.011 & 0.950 & & \\
\hline \multicolumn{5}{|c|}{ RBC SOD activity, $\mathrm{U} / \mathrm{mg} \mathrm{Hb}$} \\
\hline All & $6.96 \pm 1.40$ & $6.89 \pm 1.54$ & 0.526 & 0.741 \\
\hline Premenopause & $6.88 \pm 1.46$ & $6.86 \pm 1.57$ & 0.909 & 0.562 \\
\hline Postmenopause & $7.04 \pm 1.33$ & $6.97 \pm 1.49$ & 0.539 & 0.768 \\
\hline$p$ (pre: postmenopause)* & 0.259 & 0.640 & & \\
\hline \multicolumn{5}{|l|}{ Plasma selenium, $\mu \mathrm{g} / 1$} \\
\hline All & $56.7 \pm 11.4$ & $55.0 \pm 11.4$ & 0.044 & 0.435 \\
\hline Premenopause & $56.2 \pm 11.5$ & $54.1 \pm 10.8$ & 0.044 & 0.650 \\
\hline Postmenopause & $57.3 \pm 11.2$ & $56.7 \pm 13.1$ & 0.687 & 0.444 \\
\hline$p$ (pre: postmenopause)* & 0.404 & 0.053 & & \\
\hline \multicolumn{5}{|l|}{ Plasma vitamin $E, \mu \mathrm{g} / \mathrm{ml}$} \\
\hline All & $11.42 \pm 4.72$ & $11.53 \pm 4.41$ & 0.761 & 0.099 \\
\hline Premenopause & $10.96 \pm 4.97$ & $10.93 \pm 4.15$ & 0.937 & 0.099 \\
\hline Postmenopause & $12.00 \pm 5.18$ & $12.78 \pm 4.75$ & 0.219 & 0.099 \\
\hline$p$ (pre: postmenopause)* & 0.023 & 0.0001 & & \\
\hline \multicolumn{5}{|l|}{ Plasma vitamin $A, \mu \mathrm{g} / \mathrm{ml}$} \\
\hline All & $0.700 \pm 0.248$ & $0.722 \pm 0.231$ & 0.234 & 0.170 \\
\hline Premenopause & $0.690 \pm 0.260$ & $0.690 \pm 0.238$ & 0.957 & 0.671 \\
\hline Postmenopause & $0.711 \pm 0.160$ & $0.786 \pm 0.262$ & 0.005 & 0.003 \\
\hline$p$ (pre: postmenopause)* & 0.452 & 0.0001 & & \\
\hline \multicolumn{5}{|l|}{ Plasma TBARS, $\mathrm{nmol} / \mathrm{ml}$} \\
\hline All & $2.14 \pm 0.79$ & $2.11 \pm 0.78$ & 0.648 & 0.767 \\
\hline Premenopause & $2.06 \pm 0.76$ & $2.21 \pm 0.80$ & 0.991 & 0.624 \\
\hline Postmenopause & $2.21 \pm 0.80$ & $2.22 \pm 0.82$ & 0.957 & 0.908 \\
\hline$p$ (pre: postmenopause)* & 0.038 & 0.057 & & \\
\hline
\end{tabular}

workers, estrogen level is an additional factor affecting the redox potential. Women before menopause are protected from the toxic effects of reactive oxygen species, because estrogens play an important role as endogenous antioxidants (Krstevska et al. 2001). It has been postulated, although a final proof is still missing, that estrogens may have protective effects against lipid peroxidation (Brown et al. 2000; Chiang et al. 2004). Studies performed on rats or women receiving HRT demonstrated a quite opposite effect: increase in blood lipid peroxides and/or decrease in plasma B-carotene-precursor of vitamin A (Berg et al. 1997). Ha and Smith (2009) found significantly higher
GSH-Px activity in plasma and RBC of healthy postmenopausal women aged $70.9 \pm 3.5$ years, compared with the premenopausal ones. The Se level in their study did not differ between the pre- and postmenopausal women. Considering that the accessible results are divergent, and that there are few studies on the effects of shift work in healthy volunteers, we have decided to analyze our results with reference to the menopausal status of our subjects. Higher erythrocyte and plasma GSH-Px activities and elevated vitamin $\mathrm{E}$ levels have been found in the postmenopausal nurses working currently day shift as compared with the premenopausal ones. The changes in those antioxidants are 
Table 3 Antioxidants and TBARS levels in the blood in relation to the cumulative number of night shift work in nurses currently working in rotating system $(n=349)$

\begin{tabular}{|c|c|c|}
\hline \multirow[t]{2}{*}{ Parameters } & \multicolumn{2}{|c|}{$\begin{array}{l}\text { Total rotating shifts number during } \\
\text { the whole work life }\end{array}$} \\
\hline & $\begin{array}{l}<300 \text { months } \\
n=147\end{array}$ & $\begin{array}{l}>300 \text { months } \\
n=202\end{array}$ \\
\hline Plasma GSH-Px activity, U/ml & $0.188 \pm 0.030$ & $\begin{array}{l}0.188 \pm 0.035 \\
0.954 \\
0.936 *\end{array}$ \\
\hline RBC GSH-Px activity, U/g Hb & $20.8 \pm 5.0$ & $\begin{array}{l}21.2 \pm 4.3 \\
0.877 \\
0.856^{*}\end{array}$ \\
\hline RBC SOD activity, U/mg Hb & $7.01 \pm 1.60$ & $\begin{array}{l}6.81 \pm 1.49 \\
0.8928 \\
0.837 *\end{array}$ \\
\hline Plasma selenium, $\mu \mathrm{g} / \mathrm{l}$ & $54.1 \pm 10.7$ & $\begin{array}{l}55.7 \pm 11.8 \\
0.516 \\
0.745^{*}\end{array}$ \\
\hline Plasma vitamin $\mathrm{E}, \mu \mathrm{g} / \mathrm{ml}$ & $10.47 \pm 4.25$ & $\begin{array}{l}12.35 \pm 4.42 \\
0.314 \\
0.179 *\end{array}$ \\
\hline Plasma vitamin $\mathrm{A}, \mu \mathrm{g} / \mathrm{ml}$ & $0.666 \pm 0.247$ & $\begin{array}{l}0.763 \pm 0.209 \\
0.398 \\
0.542 *\end{array}$ \\
\hline Plasma TBARS, $\mathrm{nmol} / \mathrm{ml}$ & $2.04 \pm 0.71$ & $\begin{array}{l}2.16 \pm 0.82 \\
0.736 \\
0.669^{*}\end{array}$ \\
\hline
\end{tabular}

Results expressed as mean \pm SD

* After adjustment for age, oral contraceptive hormones use, current HRT use, smoking habits, and drinking alcohol during the last $24 \mathrm{~h}$

accompanied by increased TBARS levels in the blood plasma of the postmenopausal women.

Our comparison of GSH-Px activity both in plasma and erythrocytes of women working in the shift work system versus women working day shifts only showed reduced plasma GSH-Px in postmenopausal nurses. The RBC GSHPx activity in premenopausal nurses working rotating shifts was significantly higher than in those working only day shifts. Plasma GSH-Px and RBC GSH-Px are quite different proteins coded on different chromosomes and dominantly synthesized by different tissues.

GSH-Px protein is synthesized mainly in the kidneys, but also in the liver and other organs and released to the blood. Therefore, we may assume that the diurnal cycle of these organs affects the final activity of plasma GSH-Px. Unfortunately, such results for humans are not accessible; therefore, it is difficult to guess how light-at-night exposure may affect renal circadian cycle to modify plasma GSH-Px

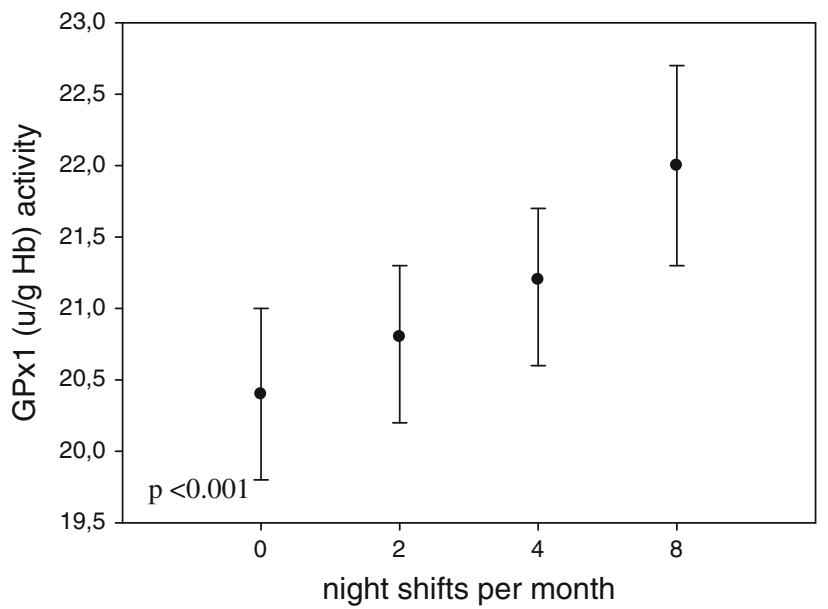

Fig. 1 Association between night shift work frequency and RBC GSH-Px activity. Comparison of RBC GSH-Px activity among nurses 0 -working on day shift only $(n=359), 2$-working less than 2 nights/month $(n=2)$, 4-working 2-4 night shifts/months $(n=19)$, 8 -working 5-8 night shifts/month $(n=320)$. Statistical analysis after adjustment for age, oral contraceptive hormone use, smoking, and drinking alcohol during the last $24 \mathrm{~h}$

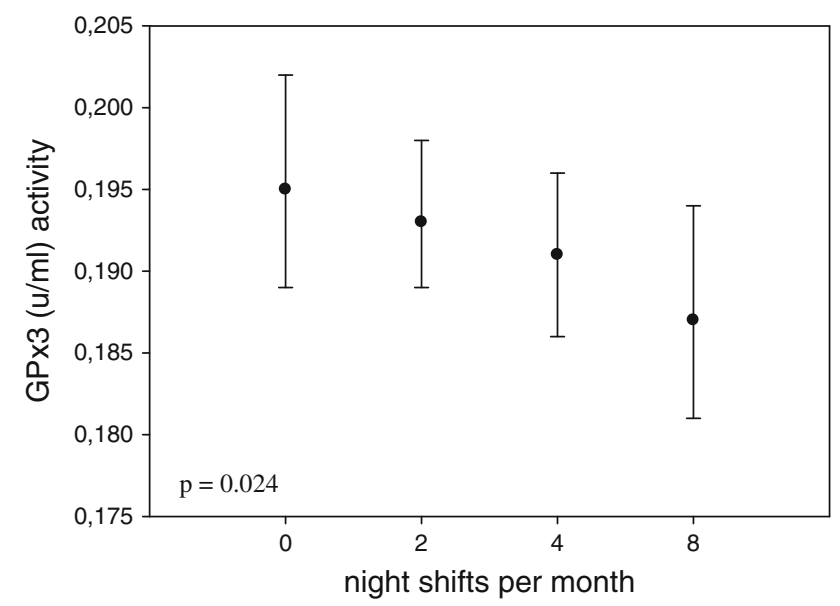

Fig. 2 Association between night shift work frequency and plasma GSH-Px activity in the postmenopausal women. Comparison of plasma GSH-Px activity among postmenopausal nurses 0-working on day shift only $(n=174), 2$-working less than 2 nights/month $(n=2)$, 4-working 2-4 night shifts/months $(n=12)$, 8-working 5-8 night shifts/month $(n=102)$. Statistical analysis after adjustment for age, oral contraceptive hormone use in the past, smoking, and drinking alcohol during the last $24 \mathrm{~h}$

activity. As the changes in plasma GSH-Px activity were analyzed immediately after termination of the exposure and differences were detected only in the postmenopausal nurses, it seems reasonable to assume that the lower activity of plasma GSH-Px results from oxidative stress associated with lower estrogen concentrations and with the light-at-night exposure of that group of women. Such assumption is supported also by gradual decrease in plasma 
GSH-Px activity in relation to frequency of night shift work per month (Fig. 2).

It is also speculated that, due to the increased oxidative stress during menopause, estrogens can act as a specific modulator of the GSH-Px activity (Ha and Smith 2009). There is evidence that the GSH-Px activity may be directly inactivated by ROS, and, at the same time, ROS may activate the transcription of mRNA GSH-Px and the synthesis of new GSH-Px molecules (Miyamoto et al. 2003). Thus, at low concentrations of melatonin, as a result of light-at-night exposure, another pathway of this protein synthesis may be activated.

The influence of light-at-night exposure and melatonin level changes on erythrocytic GSH-Px activity is more complicated. Human mature erythrocytes do not include cell nuclei, do not have mRNA GSH-Px and do not synthesize the GSH-Px protein. The observed changes in the enzyme activity are results of the influence of circadian rhythm dysregulation on immature erythrocytes. RBC GSH-Px activity detected in the present study represents the resultant of the exposure of the study nurses during the last 120 days. As the increase in RBC GSH-Px activity has been recorded in the whole study group of nurses working in a rotating shift system and, in addition, it is directly proportional to the frequency of night shift work per month, it is reasonable to suppose that some other mechanisms are involved.

In some epidemiological studies, an association between night shift work related to circadian rhythm dysregulation and increased risk of developing cancer, in particular breast cancer, has been observed (Schernhammer et al. 2001). Disruption of the circadian rhythm has been associated with cancer development in animal experiments (Levi and Schibler 2007). Melatonin plays an important role in the regulation of the circadian rhythm and has been found to make an effective antioxidant and scavenger of ROS (Reiter et al. 1995). Light-at-night exposure suppresses the melatonin synthesis, decreases the GH-Px activity, and probably also that of other enzymes from the antioxidative pathway. It also influences cellular oxidative equilibrium (Rodriguez et al. 2004). Decreased antioxidative potential facilitates generation of stress.

Davis et al. (2001) suggested that lowered nocturnal melatonin level in subjects exposed to light-at-night could increase the release of estrogens from ovaries and thus it could stimulate the turnover of epithelial stem cells, one of the factors responsible for breast cancer development. The results obtained in this study should make the basis to conduct an extensive research on the relation of the concentrations/activity of antioxidants with shift work. It is especially so in light of the data showing that high concentration of plasma $\mathrm{Se}$ is a protective factor in estimating the risk of cancer development, and high RBC GSH-Px activity is related to increased risk of breast cancer development (Rajneesh et al. 2008; Moradi et al. 2009).

Although interesting, at the present stage of the research, we have difficulties to explain the statistically significant higher levels of vitamin $\mathrm{A}$ and $\mathrm{E}$ in the plasma of postmenopausal women, irrespective of the work system. It may be explained by a mechanism meant to compensate for reduced antioxidant potential due to low estrogen levels. At the same time, the differences in the vitamin concentration between young females and postmenopausal ones may be linked to dietary habits - a reduced intake of food, limited consumption of certain products, food interactions with drugs, etc. So far, data are too limited to suggest any relationship between levels of vitamins $\mathrm{A}$ and $\mathrm{E}$ and shift work system. The results from the present study support an association between exposure to light-at-night and altered levels of some antioxidant levels in female shift workers.

Acknowledgments This project is supported by a grant from the Polish-Norwegian Research Fund (PNRF 243-AI-1/07).

Conflict of interest The authors declare that they have no conflict of interest.

Open Access This article is distributed under the terms of the Creative Commons Attribution License which permits any use, distribution, and reproduction in any medium, provided the original author(s) and the source are credited.

\section{References}

Albarrán MT, Lopez-Burillo S, Pablos MI, Reiter RJ, Agapito MT (2001) Endogenous rhythms of melatonin, total antioxidant status and superoxide dismutase activity in several tissues of chick and their inhibition by light. J Pineal Res 30:227-233

Baydas G, Ercel E, Canatan H, Donder E, Akyol A (2001) Effect of melatonin on oxidative status of rat brain, liver and kidney tissues under constant light exposure. Cell Biochem Funct 19:37-41

Baydas G, Gursu MF, Yilmaz S, Canpolat S, Yasar A, Cikim G, Canatan H (2002) Daily rhythm of glutathione peroxidase activity, lipid peroxidation and glutathione levels in tissues of pinealactomized rats. Neurosci Lett 323:195-198

Beauchamp C, Fridovich I (1971) Superoxide dismutase: improved assays and an assay applicable gels. Anal Biochem 44:276-287

Berg G, Kohlmeier L, Brenner H (1997) Use of oral contraceptives and serum beta-carotene. Eur J Clin Nutr 51:181-187

Brown L, Hoong I, Doggrell SA (2000) The heart as a target for oestrogens. Heart Lung Circ 9:113-125

Cardona F (2004) Periodic dip of lipidperoxidation in humans: a redox signal to synchronize peripheral circadian clocks. Med Hypothesis 63:841-846

Chiang K, Parthasarathy S, Santanam N (2004) Estrogen, neutrophils and oxidation. Life Sci 75:2425-2438

Costa G, Haus E, Stevens R (2010) Shift work and cancerconsideration on rationale, mechanisms, and epidemiology. Scand J Work Environ Health 36:163-179

Davis S, Mirick DK, Stevens RG (2001) Night shift work, light at night, and risk of breast cancer. J Natl Cancer Inst 93:1557-1562 
European Foundation for the Improvement of Living and Working Conditions (2007) Fourth European working conditions survey. European Foundation for the Improvement of Living and Working Conditions, Dublin

Grant SG, Melam MA, Latimer JJ, Witt-Enderby PA (2009) Melatonin and breast cancer: cellular mechanisms, clinical studies and future perspectives. Expert Rev Mol Med 11:e5. doi: $10.1017 / \mathrm{S} 1462399409000982$

Grzelinska Z, Gromadzinska J, Swiercz R, Wasowicz W (2007) Plasma concentration of vitamin $\mathrm{E}$, vitamin $\mathrm{A}$ and $\beta$-carotene in healthy men. Pol J Environ Study 16:209-213

Ha EJ, Smith AM (2009) Selenium-dependent glutathione peroxidase activity is increased in healthy post-menopausal women. Biol Trace Elem Res 131:90-95

Hansen J (2006) Risk of breast cancer after night- and shift work: current evidence and ongoing studies in Denmark. Cancer Causes Control 17:531-537

Jimenez-Ortega V, Cano P, Cardinali DP, Esquifino AI (2009) 24-hour variation in gene expression of redox pathway enzymes in rat hypothalamus: effects of melatonin treatment. Redox Rep 14:132-138

Knutsson A (2003) Health disorders of shift workers. Occup Med 53:103-108

Kolanjiappan K, Manoharan S (2005) Diurnal rhythmicity of thiobarbituric acid reactive substances and antioxidants in experimental mammary carcinogenesis. Exp Oncol 27:298-302

Kolstad HA (2008) Nightshift work and risk of breast cancer and other cancers - a critical review of the epidemiologic evidence. Scand J Work Environ Health 34:5-22

Krstevska M, Dzhekova-Stojkova S, Bosilkova G (2001) Menopause, coronary artery disease and antioxidants. Clin Chem Lab Med 39:641-644

Levi F, Schibler U (2007) Circadian rhythms: mechanisms and therapeutic implications. Annu Rev Toxicol 47:593-628

Mayo JC, Sainz RM, Antolin I, Herrera F, Martin V, Rodriguez C (2002) Melatonin regulation of antioxidant enzyme gene expression. Cell Mol Life Sci 59:1706-1713

Mirick DK, Davis S (2008) Melatonin as a biomarker of circadian dysregulation. Cancer Epidemiol Biomarkers Prev 17:33063313

Miyamoto Y, Koh Y, Park Y, Fujiwara N, Sakiyama H, Misonou Y, Ookawara T, Suzuki K, Honke K, Taniguchi N (2003) Oxidative stress caused by inactivation of glutathione peroxidase and adaptative response. Biol Chem 384:567-574

Moradi M, Hassan Eftekhari M, Talei A, Rajaei Fard A (2009) A comparative study of selenium concentration and glutathione peroxidase activity in normal and breast cancer patients. Public Health Nutr 12:59-63

Mormont MC, Levi F (1997) Circadian-system alteration during cancer processes: a review. Int J Cancer 70:241-247

Neve J (1991) Methods in determination of selenium states. J Trace EIem Electrolytes Health Dis 5:1-17
Pablos MI, Reiter RJ, Ortiz GG, Guerrero JM, Agapito MT, Chuang JI, Sewerynek E (1998) Rhythms of glutatione peroxidase and glutatione reductase in brain of chicken and their inhibition by light. Neurochem Int 32:69-75

Paglia DE, Valentine WN (1967) Studies on quantitative and qualitative characterization of erythrocyte glutathione peroxidase. J Lab Clin Med 70:158-169

Pauley SM (2004) Lighting for human circadian clock: recent research indicated that lighting has become a public health issue. Med Hypothesis 63:588-596

Polat MF, Taysi S, Gul M, Cikman O, Yilzman I, Bakan E, Erdogan F (2002) Oxidant/antioxidant status in blood of patients with malignant breast tumor and benign breast disease. Cell Biochem Funct 20:327-331

Rajneesh CP, Manimaran A, Sasikala KR, Adaikappan P (2008) Lipid peroxidation and antioxidant status in patients with breast cancer. Singapore Med J 49:640-643

Reiter RJ, Melchiorri D, Sewerynek E, Poeggeler B, Barlow-Walden L, Chuang J, Ortiz GG, Acuña-Castroviejo D (1995) A review of the evidence supporting melatonin's role as an antioxidant. J Pineal Res 18:1-11

Rodriguez C, Mayo JC, Sainz RM, Antolin I, Herrera F, Martin V, Reiter RJ (2004) Regulation of antioxidant enzymes: a significant role for melatonin. J Pineal Res 36:1-9

Schernhammer ES, Schulmeister K (2004) Melatonin and cancer risk: does light at night compromise physiologic cancer protection by lowering serum melatonin levels. Br J Cancer 90:941-943

Schernhammer ES, Laden F, Speizer FE, Willett WC, Hunter DJ, Kawachi I, Colditz GA (2001) Rotating night shifts and risk of breast cancer in women participating in the Nurses' Health Study. J Natl Cancer Inst 93:1563-1568

Straif K, Baan R, Grosse Y, Secretan B, El Ghissassi F, Bouvard V, Altieri A, Benbrahim-Tallaa L, Cogliano V (2007) Carcinogenicity of shift-work, painting, and fire-fighting. Lancet Oncol 8:1065-1066

Valko M, Izakovic M, Mazur M, Rhodes ChJ, Tesler J (2004) Role of oxygen radicals in DNA damage and cancer incidence. Mol Cell Biochem 266:37-56

Wąsowicz W, Neve J, Peretz A (1993) Optimized steps in fluorometric determination of thiobarbituric acid-reactive substances in serum: importance of extraction $\mathrm{pH}$ and influence of sample preservation and storage. Clin Chem 39:2522-2526

Yeh CC, Hou MF, Tsai SM, Lin SK, Hsiao JK, Huang JC, Wang LH, Wu SH, Hou LA, Ma H, Tsai LY (2005) Superoxide anion radical, lipid peroxides and antioxidant status in the blood of patients with breast cancer. Clin Chim Acta 361:104-111

Yeon JY, Suh YJ, Kim SW, Baik HW, Sung CJ, Kim HS, Sung MK (2011) Evaluation of dietary factors in relation to the biomarkers of oxidative stress and inflammation in breast cancer risk. Nutrition 27:912-918 